\title{
Prevención de defectos del tubo neural: 0,4 mg de ácido fólico son suficientes
}

Prevention of neural-tube defects with folic acid in China. Berry RJ, Li Z, Eickson JD, et al. For the China-U.S. Collaborative Project for Neural Tube Defect Prevention. N Engl J Med 1999;341:1485-90.

\section{Objetivo}

Determinar la eficacia de $0,4 \mathrm{mg}$ diarios de ácido fólico (a.f.), sin asociaciones, en la prevención de defectos del tubo neural (DTN).

\section{Diseño}

Estudio prospectivo de cohortes.

\section{Lugar}

Región norte de China, de Alta Tasa de DTN (RAT: 5-6 \%o nacimientos) y Región sur, de Baja Tasa (RBT: $1 \%$ ).

\section{Pacientes}

Se incluyeron 247.831 embarazadas con status conocido de DTN de sus fetos o niños; 31.960 de RAT y 215.871 RBT ( 88 y 90\% de todas las embarazadas registradas, respectivamente en el examen prenupcial).

\section{Intervención}

Se realizó una campaña de prevención de DTN en ambas regiones desde 1993 a 1995. Durante el examen prenupcial obligatorio se solicitó a las mujeres que desde entonces y hasta el final del 1er trimestre adquieran y consuman diariamente $0,4 \mathrm{mg}$ de a.f.. Trabajadores sociales registraban mensualmente fechas menstruales, tiempo y adherencia al consumo de a.f. por conteo de las píldoras restantes en cada envase. Se definió como uso periconcepcional de a.f. al consumo desde antes de la última menstruación hasta el final del 1er trimestre, uso tardío de comenzarse luego de la última menstruación y suspensión temprana si el comienzo y suspensión fueron antes de la última menstruación. Las mujeres con datos perdidos no fueron asignadas a ningún grupo y si no acordaban tomar a.f. o ya estaban en el 2 do trimestre se las consideró como no uso. Se estableció un sistema de vigilancia de defectos estructurales congénitos para nacidos vivos o mortinatos $>20$ semanas. El DTN debía diagnosticarse antes de las 6 semanas y confirmars a por la evaluación independiente (reportes y fotografías) de 3 pediatras ciegos a la categoría de uso.

\section{Medición de resultados principales}

Tasa de DTN cada 1000 embarazos >20 semanas según el uso de a.f..

\section{Resultados principales}

Hubo 275 DTN: 112 en la RAT y 163 en la RBT (1,6 y 1,3 veces más frecuente en mujeres respectivamente).

Los DTN más frecuentes fueron espina bífida, con o sin anencefalia y cráneoesquisis (casi el 50\% de los casos).

Tasas y Riesgos de DTN acorde al uso de ácido fólico.

\begin{tabular}{|c|c|c|c|c|c|c|c|c|c|c|}
\hline \multirow[t]{2}{*}{ Uso de Fólico } & \multicolumn{5}{|c|}{ Región de Alta Tasa $(\mathrm{N}=31.960)$} & \multicolumn{5}{|c|}{ Región de Baja Tasa ( $\mathrm{N}=215.871)$} \\
\hline & $N^{\circ}$ embarazos & $\begin{array}{l}\text { DTN/1000 } \\
\text { embarazos }\end{array}$ & $\begin{array}{l}\text { RRR \% } \\
\text { (IC 95\%) }\end{array}$ & RRA & NNT & $\mathrm{N}^{\circ}$ embarazos & $\begin{array}{l}\text { DTN/1000 } \\
\text { embarazos }\end{array}$ & $\begin{array}{l}\text { RRR \% } \\
\text { (IC } 95 \%)\end{array}$ & RRA & NNT \\
\hline No (grupo referencia) & 13.369 & $6,5 \%$ & - & - & - & 104.320 & $0,8 \%$ & - & - & - \\
\hline Si & 18.591 & $1,3 \%$ & $79(68-87)$ & $5,2 \%$ & 192 & 111.551 & $0,7 \%$ & $16(-14-19)$ & $0,1 \%$ & 10.000 \\
\hline Periconcepcional & 13.012 & $1,0 \%$ & $79(57-90)$ & $5,5 \%$ & 182 & 58.638 & $0,6 \%$ & $41(3-64)$ & $0,2 \%$ & 5.000 \\
\hline - adherencia $<80 \%$ & 4.898 & $1,4 \%$ & $70(30-88)$ & $5,1 \%$ & 196 & 11.643 & $0,5 \%$ & $48(-19-80)$ & $0,3 \%$ & 3.334 \\
\hline - adherencia $>80 \%$ & 8.144 & $0,7 \%$ & $85(62-94)$ & $5,8 \% 0$ & 172 & 46.995 & $0,6 \%$ & $85(-2-64)$ & $0,2 \%$ & 5.000 \\
\hline Tardío & 3.681 & $1,6 \%$ & $75(43-89)$ & $4,9 \%$ & 204 & 35.647 & $0,7 \%$ & $16(-33-45)$ & 0,1 & 10.000 \\
\hline Susp. temprana & 1.838 & $3,3 \%$ & $50(22-115)$ & $3,3 \%$ & 313 & 17.107 & $1,1 \%$ & $-37,5(-30-53)$ & $-0,3 \%$ & - \\
\hline
\end{tabular}

\section{Conclusiones}

La toma periconcepcional de 0,4 mg/día de ácido fólico reduce los DTN tanto en las RAT como en las RBT.

\section{COMENTARIO}

De las anomalías congénitas los DTN son la 2da causa de morbimortalidad del recién nacido luego de las cardiopatías ${ }^{1}$. La anencefalia es fatal y la espina bífida (la más frecuente) deja graves incapacidades. En el 80$90 \%$ de los casos no hay antecedentes familiares. Este estudio demostró eficacia* y también efectividad* pues la campaña preventiva redujo DTN en toda la población (incluida la cohorte) de 5,5 a 3,3 \%o en la RAT y de: 1 a $0,8 \%$ en la RBT. Las fortalezas de este estudio son la base poblacional*, la identificación prospectiva y casi completa de los resultados y el patrón de consumo de a.f.. Las limitaciones son las inherentes a un estudio no aleatorizado: las mujeres que decidieron tomar a.f. podrían diferir sistemáticamente de las que no lo hicieron. Sin embargo los resultados permanecieron estables luego de ajustarlos por las diferencias entre grupos (edad, NO embarazos previos, ocupación y nivel educativo). El mejor estudio $(E C C A)^{*}$ de prevención primaria de DTN2 demostró una eficacia comparable con $0,8 \mathrm{mg}$ de a.f. + multivitamínicos. Uno de los aportes más importantes de este estudio fue comprobar que bastan 0,4 mg de a.f. sin asociaciones, tal como recomienda el Servicio de Salud Pública de EEUU, 3 para reducir el riesgo de DTN. El segundo aporte tiene relación con el patrón de uso del a.f. El uso periconcepcional es el único eficaz en RBT y logra mayores beneficios en RAT, en donde una adheren- cia $80 \%$ tiene el doble de eficacia que si es $80 \%$. En RBT, epidemiológicamente más comunes como en EEUU, 4 ni el uso tardío ni la suspensión temprana son aceptables dada su aparente ineficacia. Ninguno de los potenciales factores de riesgo de DTN (incluyendo la etnia) explican las diferencias de tasas entre regiones. Sin embargo la similar tasa de DTN alcanzada con mujeres adherentes en las dos regiones, sugiere diferencias en patrones dietarios (desafortunadamente no evaluados en el estudio). Aún con la fortificación de cereales el consumo norteamericano medio de a.f. (0,2 mg/día) es la mitad de lo recomendado, 1 pues es difícil cubrir los requerimientos diarios (Ej: 6 tasas de repollitos o espinacas cocidas u 8 frutas). La fortificación debería intensificarse dado que aproximadamente el $50 \%$ de los embarazos no son planeados 1 y que el uso periconcepcional de a.f. es actualmente poco recomendado (en Dublín, RAT, la indicación fue $6 \%$ y lo recibieron $3 \%$ de las mujeres 5 y sólo el $14 \%$ de los médicos de familia canadienses conocían la recomendación exacta6). Hasta que esto se consiga, las mujeres en edad fértil deben recibir $0,4 \mathrm{mg}$ diarios de a.f desde al menos un mes antes de la concepción hasta el final del 1er trimestre para reducir el riesgo de DTN.

En la Argentina, el ácido fólico se encuentra disponible en el mercado en comprimidos de 1 y $5 \mathrm{mg}$.

\section{Dr. Agustín Ciapponi}

Unidad de Medicina Familiar y Preventiva. Hospital Italiano de Buenos Aires.

\section{Referencias}

1. Hall JG, Solehdin F. Contemporary Pediatrics, Edición Argentina 1998:6(8):26-34

2. Czeizel AE, Dudas I. Prevention of the first occurrence of neural tube-defects by periconceptional vitamin supplementation. N Engl J Med 1992;327:1832-5.

3. Recommendations for the use of folic acid to reduce the number of cases of spina bifida and other neural tube defects. MMWR Morb Mortal Wkly Rep 1992;41 (RR-14):1-7.

4. Olney R, Mulinare J. Epidemiology of neural tube defects. Ment Retard Dev Disabil Rev 1998;4:241-6.

5. Sayers GM, Hughes N, Scallan E, et al. A survey of knowledge and use of folic acid among women of child-bearing age in Dublin. J Pub Health Med 1997;19:328.

6. Koren G, Periconception folic acid supplementation: knowledge and practice of Canadian family physician. Canadian Family Physician 1997;43:851. 